\title{
O PAPEL DA ENFERMAGEM FRENTE À TENTATIVA DE SUICÍDIO NA ADOLESCÊNCIA E SEUS FATORES SOCIAIS DETERMINANTES
}

\author{
THE ROLE OF NURSING IN FRONT OF THE ATTEMPT OF SUICIDE IN \\ ADOLESCENCE AND ITS DETERMINANT SOCIAL FACTORS
}
Tiago Neves de Santana ${ }^{1}$, Raimundo José Mulado de Paiva ${ }^{2}$, David Gomes Araújo Júnior ${ }^{3}$, Anna Larissa Moraes Mesquita ${ }^{4}$, Wyarlenn Divino Machado ${ }^{4}$

Centro Universitário Estácio do Recife ${ }^{1}$; Faculdade leducara - FIED ${ }^{2}$; Universidade Estadual do Ceará (UECE) ${ }^{3}$; Universidade Federal do Ceará - UFC ${ }^{4}$

Abstract

The general objective of this article is to understand the role of nursing in the face of adolescent suicide and its determinant social factors, based on scientific literature. The methodology applied to carry out this study was an integrative literature review, using scientific productions published between 2005 and 2021, in the databases Scielo (Scientific Eletronic Library Online), VHL / Bireme (Virtual Health Library / Centro Latino -American and Caribbean Health Information), with the following descriptors: Adolescence, Suicide and Nursing. The studies obtained showed that suicide among adolescents is a serious problem and that needs special care for the whole society, either because it is a moment in life when there is a vulnerability to the psychological conflicts characteristic of this phase between childhood and childhood adult life, either due to a lack of adequate training for nurses to deal with, perceive and welcome these adolescents. Therefore, it is necessary that everyone is always attentive to signs such as changes in temperament and changes in behavior, as these characteristics are present in most of the victimized cases. Therefore, the role of nursing in the notification of new cases, in welcoming the patient and in the development of targeted preventive policies that improve both the quality of care and the prevention of new cases is of fundamental importance.
Resumo

O objetivo geral deste artigo centra-se em compreender a atuação da enfermagem perante a problemática do suicídio na adolescência e seus fatores sociais determinantes, a partir da literatura científica. A metodologia aplicada para a realização desse estudo foi uma revisão integrativa da literatura, utilizando produções científicas publicadas entre os anos de 2005 a 2021, nas bases de dados Scielo (Scientific Eletronic Library Online), BVS/Bireme (Biblioteca Virtual em Saúde/ Centro Latino-Americano e do Caribe de Informação em Saúde), com os seguintes descritores: Adolescência, Suicídio e Enfermagem. Os estudos obtidos mostraram que o suicídio entre adolescentes é um problema grave e que necessita de cuidados especiais por toda a sociedade, seja por se tratar de um momento da vida em que há uma vulnerabilidade aos conflitos psicológicos característicos dessa fase que intermeia a infância e a vida adulta, seja por uma falta de capacitação adequada dos enfermeiros para lidar, perceber e acolher esses adolescentes. Por isso, é preciso que todos estejam sempre atentos aos sinais como mudança de temperamento e mudanças de comportamento, pois essas características se fizerem presentes na maioria dos casos vitimados. Então, é de fundamental importância a atuação da enfermagem na notificação de novos casos, no acolhimento do paciente e no desenvolvimento de políticas preventivas direcionadas que melhorem tanto a qualidade no atendimento, quanto a prevenção de novos casos. 
A palavra "suicídio" deriva do latim sui (si mesmo) e caedes (ação de matar). O suicídio é uma possibilidade humana - escolher o momento da própria morte. O significado dessa escolha, no entanto, difere de acordo com circunstâncias sociais e individuais. Este ato pode ser visto como libertação, punição, coerção, fuga, alívio para o sofrimento, além de outras inúmeras formas de entendimentos, constituindo assim, uma lógica própria $^{1}$

Atualmente, o suicídio é a segunda causa de morte que mais ocorre na adolescência, sendo a sua ocorrência mais predominante nos países ocidentais. Não é um fenômeno contemporâneo, é uma realidade universal: atravessa as histórias de todas as culturas, de todos os tempos. Presta-se a múltiplas análises psicológicas, sociológicas, antropológicas, dentre outras $^{2}$.

A elevação dos índices mundiais de suicídio tem tornado esse tema um problema de repercussão global. No Brasil durante o período de 2011 a 2018 foram notificados 339.730 casos de violência autoprovocada, dos quais 154.279 $(45,4 \%)$ ocorreram na faixa etária de 15 a 29 anos, sendo 103.881 (67,3\%) nas mulheres e 50.388 (32,7\%) nos homens (BRASIL, 2019). No entanto, é possível ser prevenido, desde que haja informações, campanhas preventivas e profissionais de saúde habilitados à disposição da população ${ }^{3}$.

Nesse contexto o comportamento suicida é algo complexo e amplo mediante as suas intenções, assim como as suas consequências. Ele demostra a fragilidade que o sujeito se encontra, da mesma forma que reflete o quanto a sua vida está insuportável ao ponto de abdicar de todas as possibilidades que o futuro poderá vir a proporcionar, em prol do término do seu sofrimento propriamente dito ${ }^{1}$.

Diante da sua complexidade, o suicídio tem sido abordado sob diversos aspectos, exigindo esforços conjugados de profissionais de diferentes especialidades, de forma a evitar os riscos decorrentes de uma visão unidimensional da realidade ${ }^{2}$.

A adolescência é um período marcado por transformações biológicas e, por conseguinte, emocionais. Tal fase é distinguida por um empenho vigoroso para o adolescer, com impulsos frequentes para atuar e enfrentar a realidade; é a procura da independência. Trata-se de um processo de adaptação à realidade e domínio do ambiente ${ }^{4}$.
Trata-se de uma fase tipicamente conflituosa, pois ao mesmo tempo em que se almeja crescer, desenvolver, frequentar novos ambientes, ocorre um sentimento de saudade do passado que está deixando para trás, e o medo do futuro com os desafios que logo terá que enfrentar. Ou seja, o adolescente oscila em meio ao passado e ao futuro, entre a infância e a fase adulta, uma vez que expõe condutas muitas vezes infantis, também traz ambições de independência e de autonomia, o qual crê serem próprias de um ser crescido ${ }^{5}$.

Neste ponto é preciso que os pais estejam bastante atentos ao comportamento do adolescente, pois é nesta fase de conflito que os suicídios costumam ocorrer. Isso se deve ao fato de que neste período da vida, as pessoas costumam estar repletas de sentimento de culpa, sensíveis e emotivas ao extremo, não tendo qualquer governo sobre seus sentimentos ${ }^{4}$.

O comportamento suicida é bastante julgado por todos, sejam os próprios familiares, os amigos, ou mesmo a sociedade em si. Porém, o que se faz necessário mencionar é que o suicídio na adolescência não é um elemento legítimo da psicopatologia, este abarca múltiplas condutas psicopatológicas como igualmente, aspectos históricos, sociológicos, dentre outros ${ }^{5}$.

A assiduidade de comportamentos autodestrutivos em meio a jovens mostra-se como um desafio para a sociedade como um todo, inclusive para a saúde pública, onde preconceitos necessitam ser rescindidos, com a finalidade de que ocorra a notificação de tentativas para que deste modo haja um meio de se estudar, de forma mais arraigada, tal fenômeno e somente assim possam existir táticas de precaução de novos casos como também de reincidência ${ }^{6}$.

Este estudo justifica-se pelo alto índice dos comportamentos suicidas, sobretudo em adolescentes, uma vez que o suicídio entre adolescentes jovens é pouco investigado, e sua etiologia é complexa envolvendo além de fatores biológicos e psicológicos, o contexto socioeconômico. É de suma importância que o enfermeiro esteja preparado para esse tipo de intercorrência tendo em vista o grande número de casos e atendimentos. O enfermeiro deve estar atento à qualidade do serviço que é prestado sabendo que quanto mais eficiente for o atendimento, melhor será a resposta e o prognóstico do paciente.

A relevância da presente pesquisa surgiu pela necessidade de avaliar o papel da enfermagem no enfrentamento desta problemática. Essa temática mostra-se bastante 
proeminente no contexto atual, já que o índice de suicídios na adolescência vem crescendo de uma forma assustadora nos últimos anos e muitos são os fatores que estão envolvidos ${ }^{7}$.

A magnitude desses pensamentos, sua profundidade, o contexto em que surgem e a impossibilidade de desligar-se deles é que são fatores que distinguem um jovem saudável de um que se encontra à margem de uma crise suicida ${ }^{8}$. Dessa forma, o objetivo geral deste artigo centra-se em compreender a atuação da enfermagem perante a problemática do suicídio na adolescência e seus fatores sociais determinantes, a partir da literatura científica.

\section{Metodologia}

Esse estudo científico caracteriza-se como uma revisão integrativa, o qual tem uma fundamentação teórica que visa dar sustentação ao desenvolvimento da pesquisa, assim, a pesquisa bibliográfica caracteriza-se pelo uso de artigos, livros ou demais materiais já publicados e que em comum abordem a temática analisada para que possam em conjunto produzir um conhecimento coerente, real e efetivo ${ }^{9}$. Para a estruturação dessa revisão, as seguintes etapas foram percorridas: formação da pergunta norteadora; busca ou amostragem na literatura; coleta de dados, análise crítica do estudo; e discussão dos resultados. A pergunta norteadora foi: Como se compreende a atuação da enfermagem perante a problemática do suicídio na adolescência e seus fatores sociais determinantes, a partir da literatura científica?

Foram consultadas as seguintes bases eletrônicas: Scielo (Scientific Eletronic Library Online), BVS/Bireme (Biblioteca Virtual em Saúde/ Centro Latino-Americano e do Caribe de Informação em Saúde). O período de busca ocorreu entre os meses novembro de 2020 a fevereiro 2021.

Os descritores utilizados todos constantes dos DECS (Descritores em Ciências da Saúde) foram: "adolescência", "suicídio" e "enfermagem" e seus correspondentes na língua inglesa, com a expressão booleana "and". As estratégias de busca utilizada foi: adolescência OR adolescence AND suicídio OR suicide AND enfermagem OR nursing.

Ao realizar a busca foram encontrados 250 artigos na BVS e 86 artigos na Scielo, totalizando uma amostragem de 336 artigos, em seguida foram aplicados os critérios de elegibilidade (inclusão e exclusão) dos manuscritos. Para os critérios de inclusão foram selecionados os estudos que estivessem disponíveis de forma completo gratuitamente, no idioma português, artigos dentro da temática pesquisada e que fossem publicados entre 2005 e 2021. Em relação aos critérios de exclusão, foram considerados os estudos duplicados, de idioma estrangeiro e/ou que fugissem da temática. Após a fase de elegibilidade foram selecionados para o estudo um total de 10 (dez) artigos.

A partir da interpretação e da síntese dos resultados, os dados foram comparados e evidenciados na análise dos artigos ao referencial teórico. A partir daí, iniciaram as discussões dos resultados obtidos. Como se trata de uma revisão integrativa, o estudo não necessitou de submissão a um Comitê e Ética em Pesquisa.

\section{Resultados e Discussão}

Nesta revisão, portanto, foram utilizados 10 (dez) artigos que abordaram o suicídio na adolescência e o papel da enfermagem frente a essa problemática. Tais estudos estão compreendidos entre os anos de 2005 a 2020. Dentre os 10 artigos selecionados para compor o corpus desta revisão, a maior parte foi publicada no ano de 2020 (04 artigos), tendo um decréscimo nos anos seguintes: 2019, 2015, 2014 e 2011 com 01 artigo cada ano, e 2005 com 02 artigos. No que concerne a base da dados a predominância foi uniforme entre os 10 artigos selecionados, 05 na SCIELO e os outros 05 na LILACS.

No quadro 1 serão apresentadas as informações dos estudos selecionados para análise das publicações de acordo com o ano em que foi publicado, autores, periódicos, metodologia e síntese dos resultados. 
Quadro 1: Apresentação da síntese dos artigos inclusos nesse estudo.

\begin{tabular}{|c|c|c|c|c|c|}
\hline Ano & Autores & Título & Periódico & Tipo de estudo & Síntese dos resultados \\
\hline 2020 & SOUSA et al. & $\begin{array}{c}\text { Ideação suicida e fatores } \\
\text { associados entre escolares } \\
\text { adolescentes }\end{array}$ & $\begin{array}{c}\text { Rev Saude } \\
\text { Publica }\end{array}$ & $\begin{array}{c}\text { Estudo } \\
\text { transversal }\end{array}$ & $\begin{array}{l}\text { Os achados apresentados no estudo } \\
\text { evidenciam a importância de se } \\
\text { investigar a ideação suicida entre } \\
\text { adolescentes escolares, considerando } \\
\text { que o desfecho está relacionado a } \\
\text { diversos outros problemas e pode } \\
\text { gerar consequências maiores, como a } \\
\text { morte. }\end{array}$ \\
\hline 2020 & $\begin{array}{l}\text { ORELLANA } \\
\text { et al. }\end{array}$ & $\begin{array}{l}\text { Transtornos mentais em } \\
\text { adolescentes, jovens e } \\
\text { adultos do Consórcio de } \\
\text { Coortes de Nascimento } \\
\text { brasileiras RPS (Ribeirão } \\
\text { Preto, Pelotas e São Luís) }\end{array}$ & $\begin{array}{l}\text { Cad. Saúde } \\
\text { Pública }\end{array}$ & $\begin{array}{c}\text { Consórcio de } \\
\text { Coortes }\end{array}$ & $\begin{array}{l}\text { A maior prevalência de depressão } \\
\text { atual nos adolescentes pode ser } \\
\text { reflexo de determinantes } \\
\text { socioeconômicos da região. Portanto, } \\
\text { o elevado percentual de indivíduos em } \\
\text { risco de suicídio detectados nesses } \\
\text { estudos parece ter uma conotação } \\
\text { prática evidente, a necessidade da } \\
\text { ampliação e qualificação das } \\
\text { estratégias de prevenção, } \\
\text { especialmente entre os jovens, } \\
\text { mulheres e pessoas em desvantagem } \\
\text { socioeconômica. }\end{array}$ \\
\hline 2020 & $\begin{array}{c}\text { PESSOA } \\
\text { et al. }\end{array}$ & $\begin{array}{c}\text { Assistência de } \\
\text { Enfermagem na Atenção } \\
\text { primária à saúde de } \\
\text { adolescentes com } \\
\text { ideações suicidas }\end{array}$ & $\begin{array}{l}\text { Rev Min } \\
\text { Enferm }\end{array}$ & $\begin{array}{l}\text { Estudo do tipo } \\
\text { descritivo e } \\
\text { exploratório, com } \\
\text { abordagem } \\
\text { qualitativa }\end{array}$ & $\begin{array}{l}\text { Percebe-se, pois, que as ações em } \\
\text { saúde para o adolescente na atenção } \\
\text { primária não possuem um } \\
\text { planejamento bem definido no que diz } \\
\text { respeito ao cuidado de adolescentes } \\
\text { com ideações suicidas, resumindo suas } \\
\text { ações ao que está posto nos } \\
\text { programas de saúde } \\
\text { ministeriais. Sugere-se, ainda, que a } \\
\text { área da saúde mental seja fortalecida } \\
\text { na formação do enfermeiro, para que } \\
\text { os futuros profissionais possam } \\
\text { incorporar essa problemática no } \\
\text { cotidiano do seu trabalho, visto que o } \\
\text { suicídio em jovens é uma realidade } \\
\text { que vem aumentando e requer } \\
\text { assistência integral da Enfermagem } \\
\text { aos adolescentes. }\end{array}$ \\
\hline 2020 & $\begin{array}{c}\text { BESERRA } \\
\text { et al. }\end{array}$ & $\begin{array}{c}\text { Violência no contexto } \\
\text { escolar e ideação suicida } \\
\text { na adolescência }\end{array}$ & $\begin{array}{l}\text { Rev. } \\
\text { Enferm. } \\
\text { UFSM - } \\
\text { REUFSM }\end{array}$ & $\begin{array}{c}\text { Estudo } \\
\text { transversal }\end{array}$ & $\begin{array}{l}\text { Foi verificado associação significativa } \\
\text { da ideação suicida com a violência } \\
\text { sofrida, indicando que o envolvimento } \\
\text { em violência escolar do tipo bullying. A } \\
\text { necessidade de se elaborar ações que } \\
\text { visem à prevenção da violência e à } \\
\text { promoção da saúde do escolar é } \\
\text { emergente. Deste modo, um dos } \\
\text { profissionais de saúde que possui } \\
\text { papel fundamental na prevenção e } \\
\text { combate deste tipo de agravo é o da } \\
\text { enfermagem, na medida em que atua } \\
\text { na promoção da saúde do escolar. }\end{array}$ \\
\hline 2019 & $\begin{array}{l}\text { VELOSO } \\
\text { et al. }\end{array}$ & $\begin{array}{l}\text { Ideação suicida em } \\
\text { universitários da área da }\end{array}$ & $\begin{array}{l}\text { Rev } \\
\text { Gaúcha }\end{array}$ & $\begin{array}{l}\text { Estudo } \\
\text { transversal }\end{array}$ & $\begin{array}{l}\text { A prevalência de ideação suicida entre } \\
\text { universitários foi de } 22 \% \text { e os fatores }\end{array}$ \\
\hline
\end{tabular}


Continuação.

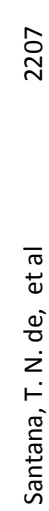

\begin{tabular}{|c|c|c|c|c|c|}
\hline & & $\begin{array}{l}\text { saúde: prevalência e } \\
\text { fatores associados }\end{array}$ & Enferm. & & $\begin{array}{l}\text { associados foram: uso de álcool, } \\
\text { tabaco e outras drogas, ser vítima de } \\
\text { bullying, ter histórico de tentativa de } \\
\text { suicídio e não frequentar o curso que } \\
\text { deseja. Considerando os fatores } \\
\text { associados a ideação suicida entre } \\
\text { universitários sugere-se ações de } \\
\text { apoio físico, mental e de saúde } \\
\text { acadêmica, a exemplo da escuta } \\
\text { qualificada por enfermeiros e } \\
\text { docentes, com vistas a oferecer } \\
\text { soluções para os universitários. }\end{array}$ \\
\hline 2015 & $\begin{array}{l}\text { TEIXEIRA } \\
\text { et al. }\end{array}$ & $\begin{array}{l}\text { O suicídio na adolescência } \\
\text { nas publicações da } \\
\text { enfermagem brasileira: } \\
\text { revisão integrativa da } \\
\text { literatura }\end{array}$ & $\begin{array}{l}\text { Rev } \\
\text { Enferm. } \\
\text { Cent. O. } \\
\text { Min. }\end{array}$ & $\begin{array}{c}\text { Revisão } \\
\text { integrativa }\end{array}$ & $\begin{array}{l}\text { Os resultados destacam a } \\
\text { multicausalidade do suicídio na } \\
\text { adolescência, os fatores de risco para } \\
\text { o suicídio e o papel do enfermeiro na } \\
\text { assistência a este sujeito. }\end{array}$ \\
\hline 2014 & $\begin{array}{l}\text { SILVA, L. L. T } \\
\text { e MADEIRA, } \\
\text { A. M. F. }\end{array}$ & $\begin{array}{c}\text { Tentativa de } \\
\text { autoextermínio entre } \\
\text { adolescentes e jovens: } \\
\text { uma análise compreensiva }\end{array}$ & $\begin{array}{l}\text { Rev } \\
\text { Enferm. } \\
\text { Cent. O. } \\
\text { Min. }\end{array}$ & $\begin{array}{c}\text { Trata-se de } \\
\text { estudo qualitativo } \\
\text { com a escolha da } \\
\text { fenomenologia } \\
\text { como trajetória } \\
\text { metodológica. }\end{array}$ & $\begin{array}{l}\text { Destaca-se a importância da atuação } \\
\text { da enfermagem na prevenção de } \\
\text { atitudes suicidas, uma vez que tanto } \\
\text { no ambiente hospitalar quanto na } \\
\text { atenção primária é o profissional de } \\
\text { enfermagem que permanece mais } \\
\text { próximo ao sujeito que é cuidado, com } \\
\text { criação de vínculos de confiança e } \\
\text { afeto. O enfermeiro precisa } \\
\text { compartilhar o universo do } \\
\text { adolescente, compreender seus } \\
\text { medos, anseios, desejos, estar aberto } \\
\text { às indagações e à postura } \\
\text { questionadora característica desse } \\
\text { sujeito. }\end{array}$ \\
\hline 2011 & $\begin{array}{l}\text { APARECIDA } \\
\text { et al. }\end{array}$ & $\begin{array}{c}\text { Assistência de } \\
\text { enfermagem às famílias de } \\
\text { indivíduos que tentaram } \\
\text { suicídio }\end{array}$ & $\begin{array}{l}\text { Esc. Anna } \\
\text { Nery }\end{array}$ & $\begin{array}{l}\text { Pesquisa com } \\
\text { abordagem } \\
\text { qualitativa. }\end{array}$ & $\begin{array}{l}\text { Foi verificado neste estudo que o } \\
\text { contato inicial com a família é breve e } \\
\text { não tem como finalidade principal } \\
\text { oferecer cuidado, apoio, zelo e } \\
\text { esclarecimentos, mas sim a coleta de } \\
\text { informações referentes à tentativa de } \\
\text { suicídio. Os profissionais entrevistados } \\
\text { apontam como fatores para a } \\
\text { precariedade de cuidado à família, as } \\
\text { difíceis condições estruturais das } \\
\text { instituições, a dinâmica de trabalho } \\
\text { estafante das unidades de emergência, } \\
\text { a grande demanda de pacientes nestes } \\
\text { setores e o despreparo profissional } \\
\text { para atuar em situações mais } \\
\text { complexas, como ocorrem nas } \\
\text { tentativas de suicídio. }\end{array}$ \\
\hline 2005 & $\begin{array}{l}\text { AVANCI, R. } \\
\text { de C; } \\
\text { PEDRAO, L; } \\
\text { COSTA } \\
\text { JUNIOR, M. } \\
\text { L. }\end{array}$ & $\begin{array}{l}\text { Perfil do adolescente que } \\
\text { tenta suicídio em uma } \\
\text { unidade de emergência }\end{array}$ & $\begin{array}{l}\text { Rev. bras. } \\
\text { enferm. }\end{array}$ & $\begin{array}{l}\text { Trata-se de uma } \\
\text { pesquisa com } \\
\text { abordagem } \\
\text { qualitativa }\end{array}$ & $\begin{array}{l}\text { Os resultados mostraram que } 77,8 \% \\
\text { dos casos pertencem ao sexo } \\
\text { feminino, predominância da faixa } \\
\text { etária entre } 15 \text { e } 19 \text { anos, estado civil } \\
\text { solteiro, cor branca, estudantes, com } \\
\text { residência em bairros de baixo poder } \\
\text { aquisitivo, utilizando a ingestão de } \\
\text { medicamentos no período diurno, e }\end{array}$ \\
\hline
\end{tabular}




\begin{tabular}{|c|c|c|c|c|c|}
\hline & & & & & $\begin{array}{l}\text { são semelhantes aos descritos em } \\
\text { outros estudos, necessitando assim } \\
\text { atenção especial. }\end{array}$ \\
\hline 2005 & $\begin{array}{l}\text { AVANCI, R. } \\
\text { de C; } \\
\text { PEDRAO, L; } \\
\text { COSTA } \\
\text { JUNIOR, M. } \\
\text { L. }\end{array}$ & $\begin{array}{l}\text { Tentativa de suicídio na } \\
\text { adolescência: } \\
\text { considerações sobre a } \\
\text { dificuldade de realização } \\
\text { diagnóstica e a abordagem } \\
\text { do profissional de } \\
\text { enfermagem }\end{array}$ & $\begin{array}{l}\text { SMAD } \\
\text { Rev. } \\
\text { Eletrônica } \\
\text { Saúde } \\
\text { Mental } \\
\text { Álcool } \\
\text { Drog. }\end{array}$ & Estudo qualitativo & $\begin{array}{l}\text { Os resultados apontaram que os casos } \\
\text { admitidos na Unidade a que foi } \\
\text { omitida a intencionalidade do ato pelo } \\
\text { adolescente e sua família, } \\
\text { apresentando dados que levam a um } \\
\text { diagnóstico de Intoxicação Exógena ao } \\
\text { invés de Tentativa de Suicídio, ou } \\
\text { ainda casos indiretos de tentativa de } \\
\text { suicídio como em acidentes de trânsito } \\
\text { em que nem se cogita a possibilidade. } \\
\text { E, até mesmo, tentativas de suicídio } \\
\text { menos graves, sem risco eminente de } \\
\text { vida em que a família ou o paciente } \\
\text { não tenha procurado atendimento } \\
\text { médico. Esses são alguns aspectos que } \\
\text { dificultam a realização do diagnóstico } \\
\text { e de estudos epidemiológicos. }\end{array}$ \\
\hline
\end{tabular}

Considerando os artigos estudados sabe-se que a adolescência se caracteriza por ser uma época de transformações tanto físicas como igualmente psicológicas e que tais transformações apresentam como consequência a dificuldade de enxergar o mundo de maneira mais simples, ou seja, de se encaixar neste novo universo. Desta forma, abre-se uma porta para o surgimento de doenças como a depressão, ou mesmo para o agravamento de quadros da mesma e por consequência levar ao suicídio ${ }^{20}$.

É preciso mencionar que o modo como a adolescência se desenvolve está presente na analogia que os jovens constituem com o próprio corpo demonstrado por amor, ódio, alegria, vergonha, prazer e raiva ${ }^{20}$.

Conforme os diversos artigos elencados neste estudo o adolescente que busca o suicídio apresenta uma nítida necessidade de criar vínculos com alguém que o entenda e que saiba ouvir, mas não o critique. Nesse sentido, o enfermeiro precisa se fazer presente perante o adolescente, prestando apoio e sem julgamentos morais $^{15,16,18}$.

Percebe-se que o suicídio na adolescência não é visto como a evidência de uma série de problemas referentes ao contexto social, embora ocorra com um indivíduo que possua uma implicação coletiva. Vale salientar que o comportamento suicida é multicausal e multidefinido, reflexo de ampla teia de fatores de risco e proteção que interagem sobre os sujeitos ${ }^{12}$.
Em síntese, os dados encontrados evidenciam a importância da identificação pelos profissionais da saúde dos fatores que estão

diretamente associados com a violência sofrida e/ou praticada que tenham relação direta ou indiretamente ao comportamento suicida, que são essenciais para a construção do conhecimento sobre violência e sociabilidade na adolescência ${ }^{13}$.

De forma geral, a finalidade do atendimento da enfermagem aos pacientes com comportamento suicida é realizar prevenção, diminuir o fluxo em hospitais e prontos atendimentos, educar e promover a saúde para melhorar o autocuidado desses indivíduos, atender integralmente as famílias e trabalhar na qualidade de vida quando o problema já está instalado. Entretanto, os enfermeiros reconhecem que no âmbito da atenção primária são poucas as atividades preventivas desenvolvidas com usuários que apresentam comportamento suicida ${ }^{15,16,17,19,20}$.

O modo como a pessoa é recebida, a atenção que o profissional dispensa e a manifestação de preocupação com o paciente quando ele chega ao serviço de saúde, é de extrema importância. Pois essa qualidade da abordagem, na emergência em saúde mental, possui significativa influência no acolhimento psicossocial desses pacientes ${ }^{21}$.

Destaca-se ainda a importância da ação da enfermagem na vigilância de atitudes suicidas, uma vez que tanto no recinto hospitalar quanto na atenção primária é o profissional de 
enfermagem que se conserva mais próximo ao sujeito que é cuidado, com criação de vínculos de confiança e ternura. O enfermeiro necessita partilhar o mundo do adolescente, compreender seus receios, ambições, aspirações, encontrar-se acessível às indagações e às atitudes questionadoras particularidades desse indivíduo. É necessário ir ao encontro dessa população, resgatá-la para os serviços de saúde, ampliando ações de atenção ao suicídio ${ }^{15,16,17,19,21}$.

Buríola $^{17}$, em seu estudo, verificou que o contato primitivo da enfermagem com a família é conciso e não tem como desígnio basilar proporcionar cuidado, apoio, zelo e esclarecimentos, mas sim a coleta de informações atinentes à tentativa de suicídio. Tal fato pode ser embasado em fatores como a precariedade de cuidado à família, as complicadas condições estruturais das instituições, a dinâmica de trabalho extenuante das unidades de emergências e, o principal, a imensa demanda de doentes nesses âmbitos ${ }^{17,19}$.

Também foram analisadas as ações dos enfermeiros junto aos familiares de pessoas que tentaram suicídio e constatou que estes profissionais abordam a família basicamente para a busca de informações referentes à tentativa de suicídio, mas há os que não abordam a família de forma alguma. Os enfermeiros que não acolhem a família reconhecem que não prestam assistência adequada e culpam-se por não terem condições para oferecer um atendimento mais humanizado, justificando sua atitude de abandono da família em todos os momentos das entrevistas $^{17}$.

Diante de todos os artigos estudados pode-se observar que o profissional de enfermagem é constitucional durante o processo terapêutico. Precisa buscar estabelecer um relacionamento terapêutico com o paciente, uma relação de confiança, necessita escutar o paciente sem efetivar ponderações de importância e consentir que ele próprio concretize a reconstrução dos significados dos suas amarguras e conflitos. Porém, esses profissionais carecem ser preparados e qualificados para esse tipo de abordagem $^{15,16,17,18,19}$.

$\mathrm{O}$ adolescente que tentou o suicídio, assim como em todas as idades, deve ser acolhido e seu sofrimento deve ser compreendido e respeitado por todos os profissionais de saúde. Os estudos de Silva ${ }^{15}$ corroboraram com os de Silva ${ }^{17}$ quando concluem que o profissional de enfermagem é fundamental durante o processo terapêutico e deve procurar estabelecer uma relação de confiança, ouvir o paciente sem realizar juízos de valor e permitir que ele próprio realize a reconstrução dos significados dos seus sofrimentos e conflitos ${ }^{20}$.

No entanto, é consenso nos estudos que profissionais precisam ser qualificados para esse tipo de abordagem. Esses aspectos devem ser reforçados principalmente durante o curso de graduação em enfermagem. Também devem ser realizados programas intra-hospitalares, onde esse tema possa ser abordado e discutido, a fim de se romper tabus e minimizar a discriminação ${ }^{19}$.

Quando se dispõe de profissionais de enfermagem qualificados que realizam uma abordagem terapêutica com o paciente suspeito de tentativa de suicídio, aumenta-se a chance de diagnosticar corretamente ${ }^{19,22}$. Esses profissionais têm um contato muito próximo e contínuo com os pacientes, observa-se que os mesmos sentem-se mais à vontade ao lado desse profissional do que ao lado da equipe médica, talvez devido à diferença de status social de ambas as profissões e a síndrome do jaleco branco $^{22}$.

Dessa forma, o paciente, durante relacionamento interpessoal com o profissional de enfermagem, tende a se desarmar, revelando fatos que não haviam dito a outros profissionais. Isso acontece geralmente durante atividades do cotidiano como: no momento do banho, da alimentação ou de uma atividade de descontração ${ }^{22}$.

Os enfermeiros dos atendimentos de urgência, por apresentarem um contato mais próximo e direto com o paciente, a exemplo daquele que tenta suicídio, acabam por se tornar atores fundamentais no cuidado. Entretanto, muitas vezes, esse processo é traduzido em uma perspectiva clínica, pautada na intervenção técnica, sem reconhecer a subjetividade e a história de vida do indivíduo ${ }^{2}$.

Os profissionais de enfermagem compartilham uma atitude desfavorável perante o comportamento suicida e esse resultado está de acordo com uma sociedade que, sendo mortal, rejeita a morte, que deixou de ser admitida como um fenômeno natural necessário e é considerada como um fracasso, tanto pela sociedade como pelo sistema de saúde ${ }^{23}$.

Para o atendimento ao usuário com comportamento suicida, é importante que o trabalho seja realizado em equipe. Os profissionais que atuam na atenção básica, por ficarem em contato mais próximo e duradouro com a comunidade, estão em posição privilegiada para atuação eficaz na prevenção do 
suicídio por meio da detecção precoce dos transtornos mentais, da avaliação da "rede de proteção social" de pacientes em risco de suicídio e da criação de estratégias de reforço dessa rede $^{23}$.

No entanto, estudos mostraram que como parte da sociedade, o profissional de enfermagem possui suas crenças ou mitos que podem interferir em sua atuação profissional influenciando na assistência ao paciente com conduta suicida ${ }^{2}$. É necessário uma capacitação dos enfermeiros quanto ao atendimento à pessoa com tendências suicidas para que sejam minimizadas qualquer ativação de gatilhos, tentando desta forma "não falar sobre o suicídio" para não induzir essa conduta no paciente, porém falar sobre o suicídio com uma pessoa que está correndo esse risco, ao invés de incitar ou provocar essa ideia, reduz o perigo de cometê-lo e pode ser a única possibilidade que o sujeito oferece para analisar seus propósitos de dar fim à vida ${ }^{2,17}$.

\section{Considerações finais}

Sabe-se que o suicídio entre adolescentes é um problema que atinge toda a sociedade. Sendo assim, é preciso que todos estejam sempre atentos aos sinais como mudança de temperamento e mudanças de comportamento (como isolamento e afastamento do ciclo social), pois essas características se fizerem presentes na maioria dos casos vitimados.

Pode-se observar que o suicídio é um problema de saúde pública e que há necessidade de organizar programas preventivos, informativos e esclarecedores na tentativa de minimizar as ocorrências deste ato. Também há necessidade dos adolescentes serem ouvidos e compreendidos sem pré-julgamentos, por profissionais habilitados.

O suicídio é um ato de total agressividade, o qual pode ser capturado pelos profissionais de saúde, não sendo infrequente descobrir um tratamento individualizado para os pacientes que optaram por atentar contra a própria vida. A incompreensão acerca do ato suicida gera desconforto emocional ao ter que prestar auxílio para esse paciente, pois os profissionais da enfermagem estão acostumados a prestarem seus cuidados para pessoas que encontram-se doentes por outros e diversos motivos. Neste sentido os profissionais de saúde não se encontram isentos à carga cultural de desprezo e preconceito frente ao tentame de autoextermínio.
Faz-se necessário mencionar que o desafio maior para a realização desse estudo foi encontrar artigos relacionados diretamente com a temática. Pode-se afirmar que há muitos artigos com a temática suicídio, porém quando liga-se suicídio, adolescente e papel da enfermagem, a situação muda e o número restringe-se bastante ao ponto numérico bastante ínfimo.

Portanto, sugere-se a realização de mais pesquisas que evidenciem possibilidades de cuidados de enfermagem ao adolescente em situação de suicídio. Além disso, é necessária uma melhoria no aprimoramento do processo de formação do enfermeiro que contemple os cuidados da enfermagem diante dos diversos contextos do suicídio para que lide melhor com as diversas situações que possam surgir. Salientase a importância de se debater sobre o assunto suicídio na adolescência para a sua desmistificação, prevenção e consequentemente, promoção à vida.

\section{Referências}

1. Fukumitsu, KO. Suicídio e luto: histórias de filhos sobreviventes. 1. ed. São Paulo: Digital Publish \& Print, 2013.

2. Vidal CEL, Gontijo ED. Tentativas de suicídio e o acolhimento nos serviços de urgência: a percepção de quem tenta. Cad. saúde colet. 2013; 21(2):108-114.

3. Brasil, Ministério da Saúde. Secretária de Vigilância em Saúde. Perfil epidemiológico dos casos notificados de violência autoprovocada e óbitos por suicídio entre jovens de 15 a 29 anos no Brasil, 2011 a 2018. Brasília (DF): Ministério da Saúde; 2019; 50(24): 1-14.

4. Braga LL. Dell'aglio DD. Suicídio na adolescência: fatores de risco, depressão e gênero.Context. Clín. Jan - Jul 2013; 6(1):1-14.

5. Botega, NJ. Crise suicida: avaliação e manejo. 1a Ed. Porto Alegre: Artmed; 2015.

6. Souza LDM, Ores L, Oliveira GT, Cruzeiro ALS, Silva RA, Pinheiro RT, Horta BL. Ideação suicida na adolescência: prevalência e fatores associados. Jorn. Brasileiro de Psiq. 2010; 59(4): 286-292.

7. Reisdorfer $N$. et al. Suicídio na voz de profissionais de enfermagem e estratégias de intervenção diante de comportamento suicida. Ver. Enferm. UFSM. Abr-Jun 2015; 5(2): 295-304

8. Borges VR. Werlang BSG. Copatti, M. Ideação suicida em adolescentes de 13 a 17 anos. Barbarói. Jan-Jul 2008; 1(28):109-123.

9. Prodanov CC. Freitas EC. Metodologia do Trabalho Cientifico: métodos e técnicas de 
pesquisa e do trabalho acadêmico. 2 ed. Novo Hamburgo: FEEVALE; 2013.

10. Sousa CMS, Mascarenhas MDM, Gomes KRO, Rodrigues MTP, Miranda CES, Frota KMG. Ideação suicida e fatores associados entre escolares adolescentes. Rev. Saúde Pública. 2020; 40:e20180144.

11. Orellana JDY. et al. Transtornos mentais em adolescentes, jovens e adultos do Consórcio de Coortes de Nascimento brasileiras RPS (Ribeirão Preto, Pelotas e São Luís). Cad. Saúde Pública. 2020; 36(2):e00154319.

12. Pessoa, DMS. et al. Assistência de enfermagem na atenção primária à saúde de adolescentes com ideações suicidas. Rev Min Enferm. 2020; 24(1290): 1-8.

13. Beserra, MA. et al. Violência no contexto escolar e ideação suicida na adolescência. Rev. Enferm. UFSM - REUFSM. 2020; 10(71):1-18.

14. Veloso LUP, Lima CLS, Sales JCS, Monteiro CFS, Gonçalves AMS, Silva Júnior FJG. Ideação suicida em universitários da área da saúde: prevalência e fatores associados. Rev. Gaúcha Enferm. 2019; 40:e20180144.

15. Silva LLT, Alvim CG, Costa CC, Ramos TM, Costa EE. O suicídio na adolescência nas publicações da enfermagem brasileira: revisão integrativa da literatura. R. Enferm. Cent. O. Min. set-dez 2015; 5(3):1871-1884.

16. Silva LLT, Madeira AMF. Tentativa de autoextermínio entre adolescentes e jovens: uma análise compreensiva. R. Enferm. Cent. O. Min. 2014 set-dez; 3(4):1281-1289

17. Buriola AA, Arnauts I, Decesaro MN, Oliveira MLF, Marcon SS. Assistência de enfermagem às famílias de indivíduos que tentaram suicídio. Esc Anna Nery. Out-dez 2011; 15(4):710-716

18. Avanci RC, Pedrão LJ, Costa Júnior ML. Perfil do adolescente que tenta suicídio em uma unidade de emergência. Rev Bras Enferm. Set-out 2005; 58(5):535-9.

19 .Avanci RC, Pedrão LJ, Júnior MLC. Tentativa de suicídio na adolescência: considerações sobre a dificuldade de realização diagnóstica e a abordagem do profissional de enfermagem.SMAD, Rev. Elet.Saúd Ment Álc Drog. (Ed. port.). 2005 1(1):1-8 .

20. Monteiro P. Psicologia e Psiquiatria da Infância e Adolescência. 1a Ed. Lisboa: Lidel; 2014.

21. Moura, R. Narrativas sobre suicídio, cultura e trabalho em um município colonizado por alemães [tese de doutorado]. Porto Alegre (RS): Programa de pós-graduação em enfermagem, Universidade Federal do Rio Grande do Sul; 2016.
22. SÁ ACA, Medeiros MFN, Diniz Sá ACA, Medeiros MFN, Diniz ERS, Silva MLN, Medeiros SS. Percepções dos profissionais de enfermagem acerca do cuidar do paciente suicida. FIEP Bulletin. 2012; 82(edição especial).

23. Meleiro AMAS. A complexidade multidimensional no processo suicida. Rev. Especial Neuropsiquiatria. Mai-jun 2013; 70(1): 12-24.

\section{Endereço para Correspondência}

Tiago Neves de Santana

Faculdade IEducare - FIED

R. Conselheiro João Lourenço, n 406 - Centro

Tianguá - CE

CEP: $62320-000$

E-mail: tiagonds@hotmail.com

Recebido em 14/03/2021

Aprovado em 17/04/2021

Publicado em 15/06/2021 